\title{
Effect of specific exercise-based football injury prevention programmes on the overall injury rate in football: a systematic review and meta-analysis of the FIFA 11 and 11+ programmes
}

\author{
Kristian Thorborg, ${ }^{1,2}$ Kasper Kühn Krommes, ${ }^{1,3}$ Ernest Esteve, ${ }^{4,5}$ Mikkel Bek Clausen, ${ }^{6}$ \\ Else Marie Bartels, ${ }^{7}$ Michael Skovdal Rathleff ${ }^{3,8,9}$
}

\begin{abstract}
- Additional material is published online only. To view please visit the journal online (http://dx.doi.org/10.1136/ bjsports-2016-097066).
\end{abstract}

For numbered affiliations see end of article.

\section{Correspondence to} Dr Kristian Thorborg, Department of Orthopaedic Surgery, Sports Orthopedic Research Center-Copenhagen (SORC-C), Amager-Hvidovre Hospital, Faculty of Health Sciences, Copenhagen University, Kettegårds Allé 30, Hvidovre 2650, Denmark; kristianthorborg@hotmail.com

Accepted 23 December 2016 Published Online First 13 January 2017

\section{CrossMark}

To cite: Thorborg $K$ Krommes KK, Esteve $\mathrm{E}_{\text {, }}$ et al. Br J Sports Med 2017:51:562-571.

\section{ABSTRACT}

Objective To investigate the effect of FIFA injury prevention programmes in football (FIFA 11 and FIFA 11+).

Design Systematic review and meta-analysis.

Eligibility criteria for selecting studies

Randomised controlled trials comparing the FIFA injury prevention programmes with a control (no or sham intervention) among football players.

Data sources MEDLINE via PubMed, EMBASE via OVID, CINAHL via Ebsco, Web of Science, SportDiscus and Cochrane Central Register of Controlled Trials, from 2004 to 14 March 2016.

Results 6 cluster-randomised controlled trials had assessed the effect of FIFA injury prevention programmes compared with controls on the overall football injury incidence in recreational/subelite football. These studies included 2 specific exercise-based injury prevention programmes: FIFA 11 (2 studies) and FIFA 11+ (4 studies). The primary analysis showed a reduction in the overall injury risk ratio of 0.75 ( $95 \% \mathrm{Cl} 0.57$ to 0.98$), p=0.04$, in favour of the FIFA injury prevention programmes. Secondary analyses revealed that when pooling the 4 studies applying the FIFA $11+$ prevention programme, a reduction in the overall injury risk ratio (incidence rate ratio (IRR) $0.61 ; 95 \%$ $\mathrm{Cl} 0.48$ to $0.77, p<0.001$ ) was present in favour of the FIFA 11+ prevention programme. No reduction was present when pooling the 2 studies including the FIFA 11 prevention programme (IRR $0.99 ; 95 \% \mathrm{Cl} 0.80$ to 1.23 , $\mathrm{p}=0.940$ ).

Conclusions An injury-preventing effect of the FIFA injury prevention programmes compared with controls was shown in football. This effect was induced by the FIFA 11+ prevention programme which has a substantial injurypreventing effect by reducing football injuries by $39 \%$, whereas a preventive effect of the FIFA 11 prevention programme could not be documented.

Trial registration number PROSPERO CRD42015024120.

\section{INTRODUCTION}

FIFA estimates that more than one-quarter of a billion people around the world regularly participate in football (soccer). ${ }^{1}$ Football has been recognised, together with running, as one of the most promising sports and leisure time activities to improve health. ${ }^{2}$ Football improves cardiovascular and metabolic health, ${ }^{2}$ and diminishes risk factors for lifestyle diseases, such as diabetes and hypertension. ${ }^{3}$ However, football also includes an inherent risk of injury, ${ }^{4} 5$ which is why injury prevention in football is crucial. ${ }^{6}$

European data show that millions of sportsrelated injuries occur each year and require medical attention and of all sports-related injuries seen in general practice, about one in four are footballrelated. ${ }^{7}$ Furthermore, 5.8 million people each year are treated at hospitals in Europe due to injuries associated with sports. ${ }^{8}$ Team ball sports account for almost half of all hospital-related sports injury treatment-and football accounts for two-third of these. ${ }^{8}$ Since 2004, FIFA has focused on strategies for injury prevention by introducing FIFA Medical Assessment and Research Centre (F-MARC) prevention programmes, known as the FIFA injury prevention programmes, and assessed their effects on football injury rates. ${ }^{9}$ These programmes include specific strengthening, balancing and jumping/ landing exercises, and are to be included during a structured warm-up session. The goal of the programmes is to improve strength, balance and jumping/landing ability, which may lead to injury reduction. ${ }^{10-12}$ Two variations of such programmes have been developed and provided by FIFA, the FIFA 11 and the FIFA $11+$ prevention programme. ${ }^{10}$ The FIFA $11+$ is a revised version of the original FIFA 11 prevention programme. ${ }^{10-12}$ The FIFA $11+$ includes similar key exercises as the FIFA 11 with minor additions, including a more dynamic warm-up and a more specific progression model for the included exercises to allow for more variation and optimising physical improvement (figure 1). ${ }^{10-12}$ The programmes have been tested in different football cohorts and individual studies, but with varying effects on injury estimates. ${ }^{10}$ Findings of no differences in injury estimates from single studies cannot, however, be considered confirmation of no effect. ${ }^{10}$ This may simply be due to insufficient power to detect reductions in injury rates of $<40 \%$, which the first FIFA injury prevention programme trial was powered to detect. ${ }^{12}$ Pooling data from individual studies into a meta-analysis offers an opportunity to increase statistical power and test whether the FIFA injury prevention programmes are associated with injury reduction, as originally hypothesised in the initial studies where FIFA was involved. ${ }^{10-12}$

Since the specific strategic goal of the F-MARC since 2009 has been proclaimed to be: 'to prevent football injuries and to promote football as a health-enhancing leisure activity, improving social 


\begin{tabular}{|c|c|}
\hline \multicolumn{2}{|c|}{$\begin{array}{l}\text { FIFA } 11 \text { prevention programme } \\
10-15 \text { minutes duration in total after familiarisation }\end{array}$} \\
\hline Exercises & $\begin{array}{l}\text { Repetitions (reps) } \\
\text { Seconds (sec) }\end{array}$ \\
\hline \multicolumn{2}{|l|}{ Core stability } \\
\hline $\begin{array}{l}\text { The bench } \\
\text { Sideways bench }\end{array}$ & $\begin{array}{l}4 \times 15 \mathrm{sec} \\
2 \times 15 \mathrm{sec} \text { each side }\end{array}$ \\
\hline \multicolumn{2}{|l|}{ Balance } \\
\hline $\begin{array}{l}\text { Cross-country skiing } \\
\text { Chest pass in single-leg stance } \\
\text { Forward bend in single-leg stance } \\
\text { Figure-of-eights in single-leg stance }\end{array}$ & $\begin{array}{l}2 \times 15 \text { sec each leg } \\
3 \times 15 \text { sec each leg } \\
3 \times 15 \text { sec each leg } \\
3 \times 15 \text { sec each leg }\end{array}$ \\
\hline \multicolumn{2}{|l|}{ Plyometrics } \\
\hline $\begin{array}{l}\text { Line jumps } \\
\text { Zigzag shuffle }(20 \mathrm{~m}) \\
\text { Bounding }(20 \mathrm{~m})\end{array}$ & $\begin{array}{l}15 \text { jumps of each type } \\
2 \text { reps in each direction } \\
3 \times 10-15 \text { jumps }\end{array}$ \\
\hline \multicolumn{2}{|l|}{$\begin{array}{l}\text { Strength } \\
\text { Nordic hamstring }\end{array}$} \\
\hline Nordic hamstring & 5 reps \\
\hline
\end{tabular}

\begin{tabular}{|c|c|}
\hline $\begin{array}{l}\text { FIFA 11+ prevention programme } \\
20 \text { minutes duration in total after famil }\end{array}$ & ation \\
\hline Exercises & $\begin{array}{l}\text { Repetitions (reps) } \\
\text { Seconds (sec) }\end{array}$ \\
\hline Running exercises & \\
\hline Running, straight ahead & 2 reps \\
\hline Running, hip out & 2 reps \\
\hline Running, hip in & 2 reps \\
\hline Running, circling & 2 reps \\
\hline Running and jumping & 2 reps \\
\hline Running, quick run & 2 reps \\
\hline Strength, plyometrics, balance & \\
\hline The plank (The bench): & \\
\hline Level 1: both legs & $3 \times 20-30 \mathrm{sec}$ \\
\hline Level 2: alternate legs & $3 \times 20-30 \mathrm{sec}$ \\
\hline Level 3: one leg lift & $3 \times 20-30 \mathrm{sec}$ \\
\hline Side plank (Sideways bench): & \\
\hline Level 1: static & $3 \times 20-30$ sec each side \\
\hline Level 2: dynamic & $3 \times 20-30$ sec each side \\
\hline Level 3: with leg lift & $3 \times 20-30$ sec each side \\
\hline Nordic hamstring: & \\
\hline Level 1 & $3-5$ reps \\
\hline Level 2 & $7-10$ reps \\
\hline Level 3 & $12-15$ reps \\
\hline Single leg balance: & \\
\hline Level 1: holding ball & $2 \times 30$ sec each leg \\
\hline Level 2: throwing ball with partner & $2 \times 30$ sec each leg \\
\hline Level 3: testing partner & $2 \times 30 \mathrm{sec}$ each leg \\
\hline Squats: & \\
\hline Level 1: with heels raised & $2 \times 30 \mathrm{sec}$ \\
\hline Level 2: walking lunges & $2 \times 30 \mathrm{sec}$ \\
\hline Level 3: one leg squats & $2 \times 10 \mathrm{sec}$ each leg \\
\hline Jumping: & \\
\hline Level 1: vertical jumps & $2 \times 30 \mathrm{sec}$ \\
\hline Level 2: lateral jumps & $2 \times 30 \mathrm{sec}$ \\
\hline Level 3: box jumps & $2 \times 30 \mathrm{sec}$ \\
\hline Running exercises & \\
\hline Running over pitch & 2 reps \\
\hline Bounding run & 2 reps \\
\hline Running and cutting & 2 reps \\
\hline
\end{tabular}

Figure 1 Specific characteristics and differences of the FIFA 11 prevention programme and the FIFA 11+prevention programme. Similar types of grey shade indicate similar types of exercise.

behaviour,, 6913 investigating the effect of the FIFA injury prevention programmes seems more timely and relevant than ever. Until now, only narrative reviews and systematic reviews including results from randomised and observational studies have been published. $^{6} 10 \quad 14$ We therefore carried out a comprehensive and up-to-date systematic review and meta-analysis of the effects of the FIFA injury prevention programmes in football, including only randomised controlled trials, to provide level 1 evidence in this field.

\section{METHODS}

We used the Preferred Reporting Items for Systematic Reviews and Meta-analyses (PRISMA) as a guideline for this study. ${ }^{15}$ The study was registered at PROSPERO (ID=CRD42015024120), and a publicly available comprehensive study protocol including data extraction forms was uploaded at the following website: http://vbn.aau.dk/files/229186677/The_effect_of_the_FIFA_11 prevention_programmes_on_the_overall_injury_rate_in_football a_systematic_review_and_meta_analysis_version1_1.p.pd

\section{Deviations from study registration and study protocol}

Agreement by raters on risk of bias decisions for the included randomised controlled studies was calculated as a percentage of agreement and $\kappa$ values, and included in the results. Since the secondary analysis concerning type of programme showed that only the FIFA $11+$ prevention programme was effective in reducing injuries, all secondary outcomes concerning lower limb, hamstring, knee and ankle injuries were only analysed in relation to this programme. Furthermore, a post hoc analysis on hip/groin injury in relation to this programme was also included. Preplanned secondary analyses on the incidence rate ratio (IRR) in the following subgroups: gender (male and female), and mean age groups (youth ( $<19$ years), seniors (19-30 years), old girls/boys (31-39 years) and veterans ( $>39$ years)) were not conducted, as the included studies did not allow making meaningful comparisons with only six studies, where studies with male $(n=3)$ and female participants $(n=3)$ significantly differed in the age group they targeted. The predefined secondary analysis of compliance at team level was not performed as all team-level data could not be obtained from the corresponding authors of the included studies. Instead, the preplanned analysis of the association between prevention programme compliance and injury incidence was further supported by a post hoc analysis of the association between prevention programme compliance and the overall injury IRR from each study to accommodate for the 
risk of substantial variance in injury incidence between studies due to other factors than the FIFA injury prevention programmes.

\section{Eligibility criteria}

We included only randomised or cluster-randomised controlled trials comparing the FIFA injury prevention programmes with a control (no or sham intervention) among football players. To be included, studies were required to fulfil the following criteria: (1) the full-text paper published in a peer-reviewed journal was available; (2) the study contained original data from a randomised controlled or a cluster-randomised trial; (3) the preventive effect of FIFA 11 or the FIFA $11+$ prevention programme was evaluated; (4) only football players were included; and (5) football injury was an outcome. For the assessment of harms (adverse events), we also included all other original studies or reports including practical execution of FIFA injury prevention programmes in football.

\section{Literature search and study selection}

We systematically searched the following bibliographic databases: MEDLINE via PubMed, EMBASE via OVID, CINAHL via Ebsco, Web of Science, SportDiscus and Cochrane Central Register of Controlled Trials, from 2004 to 14 March 2016, as the FIFA injury prevention programmes were initiated and implemented from 2004 to $2005 .^{9}{ }^{13}$ A hand search of the reference lists of relevant articles was also conducted for other potentially relevant references, and F-MARC was contacted to verify if any important FIFA 11 or FIFA $11+$ studies/publications did not appear from the search. No restriction on language was included in the search. The following search strategy was tested and found to be the most valid and efficient across databases, and was applied in all the databases aforementioned: (fifa OR f-marc OR fmarc OR prevention program* OR warm-up program* OR warmup program* OR the11) AND (football OR foot ball OR soccer). Possible relevant studies, identified by titles and abstracts from the search, were downloaded into Reference Manager V.14 (Thomson Reuters, USA) and duplicates were removed. Two authors (KT and KKK) independently performed the selection of studies based on the title and abstract provided by the bibliographic databases. This was followed by full-text evaluation of the selected studies from the first selection step. Disagreement between the two reviewers was solved by discussion. If consensus was not achieved, a third reviewer (EMB) was involved.

\section{Data extraction}

Two reviewers (EE and $\mathrm{MBC}$ ) independently extracted data using a specifically designed standardised data extracting form (see study protocol), and afterwards the reviewers compared the extracted data for consistency. All inconsistencies between the two forms were resolved by discussion between the two data extractors. Any disagreement between the data extractors after the initial discussion related to inconsistencies between the two individual data extractions was to be solved by involving a third person (EMB). General study information, participants and intervention characteristics, compliance, adverse events, withdrawals and outcome measures were extracted. Where data were not available from tables or the results section, the authors of the study in question were contacted by email, with one reminder after 2 weeks, if they did not respond to the first email. Data obtained from authors not available from the articles can be seen in table 1 , indicated by asterisks.

\section{Primary outcome}

Effect of FIFA injury prevention programmes on football injury rates

The primary outcome was overall injury incidence defined as the total number of injuries per 1000 hours of football exposure. This included all injuries (overuse and traumatic) sustained during the study period in training and match play.

\section{Secondary outcomes}

Effect of FIFA injury prevention programmes on football injury rates

Secondary outcomes were lower limb injury incidence and region-specific injury incidence for hamstring, hip/groin, knee and ankle, all defined as the number of injuries per 1000 hours of football exposure, respectively. This included all injuries (overuse and traumatic) in each category sustained during the study period in training and match play.

\section{Compliance with the FIFA injury prevention programmes and its} association with football injury rates

In the present study, compliance with the intervention was defined and estimated as the number of FIFA injury prevention programme sessions performed at team level during the intervention period divided by the length of the intervention period in months. The mean compliance for each study included in the primary analysis was estimated at team level from data available from included trials. For the same trials, the compliance for each individual team was estimated from similar data, at team level, obtained directly from the authors of the original trials. Accordingly, data at team level were obtained on: total number of injuries; total exposure time (hours); number of FIFA injury prevention programme sessions performed, and the duration of the FIFA injury prevention programme exercise period (months). The first author of this systematic review (KT) contacted corresponding authors of cluster-randomised studies included in the primary analysis concerning these compliance/ injury data, and asked them to provide this information in a prespecified data extraction form on compliance and injury rates at team level (study protocol).

\section{Harms resulting from the execution of the FIFA injury prevention programmes}

The number and type(s) of adverse effects resulting from the actual execution of the FIFA injury prevention programmes (experienced while performing the prevention exercises) were obtained from all identifiable studies including practical execution of these programmes.

\section{Synthesis of results}

\section{Effect of FIFA injury prevention programmes on football}

injury rates

For the primary analysis on the effects of the FIFA injury prevention programmes on overall injury rates, we calculated the pooled overall injury incidence for intervention and groups separately using data on injuries and exposure from all included cluster-randomised studies. If the data used to calculate the injury incidence were not available in the published article, the first author (KT) of the systematic review requested the missing data from the author(s). All cluster-randomised trials were adjusted for cluster effect in all pooled analyses. Since only one included study ${ }^{11}$ reported cluster-adjusted estimates, we used the intracluster correlation coefficient (ICC) from their trial on all trials to adjust for a potential cluster effect by calculating the 
Table 1 Summary of included RCT studies investigating the effect of FIFA injury prevention programmes

\begin{tabular}{|c|c|c|c|c|c|c|c|c|}
\hline $\begin{array}{l}\text { FIFA } \\
\text { programme }\end{array}$ & Study & Population & Intervention & $\begin{array}{l}\text { Follow-up } \\
\text { (months) }\end{array}$ & Randomised & Analysed & $\begin{array}{l}\text { Total } \\
\text { exposure }\end{array}$ & $\begin{array}{l}\text { Injuries } \\
\text { overall }\end{array}$ \\
\hline \multirow[t]{2}{*}{ FIFA 11} & $\begin{array}{l}\text { Steffen et } a l^{12} \\
(2008)\end{array}$ & $\begin{array}{l}\text { Female, youth } \\
\text { (13-17 years) }\end{array}$ & $\begin{array}{l}\text { The 11: A 10-15 min } \\
\text { exercise programme } \\
\text { for trunk and lower } \\
\text { extremity }\end{array}$ & $\approx 8$ & $\begin{array}{l}\text { IG: } 59 \text { teams; } \\
1100 \text { players } \\
\text { CG: } 54 \text { teams; } \\
1000 \text { players } \\
\text { Total: } 113 \text { teams; } \\
2100 \text { players }\end{array}$ & $\begin{array}{l}\text { IG: } 58 \text { teams; } \\
1073 \text { players } \\
\text { CG: } 51 \text { teams; } \\
947 \text { players } \\
\text { Total: } 109 \\
\text { teams; } 2020 \\
\text { players }\end{array}$ & $\begin{array}{l}\text { IG: } \\
66423 \text { hours } \\
\text { CG: } \\
65725 \text { hours }\end{array}$ & $\begin{array}{l}\text { IG: } 242 \\
\text { injuries } \\
\text { CG: } 241 \\
\text { injuries }\end{array}$ \\
\hline & $\begin{array}{l}\text { van Beijsterveldt } \\
\text { et } a l^{21}(2012)\end{array}$ & $\begin{array}{l}\text { Male, senior } \\
\text { (18-40 years) }\end{array}$ & & $\approx 9$ & $\begin{array}{l}\text { IG: } 11 \text { teams; } 241 \\
\text { players } \\
\text { CG: } 12 \text { teams; } 246 \\
\text { players } \\
\text { Total: } 23 \text { teams; } \\
487 \text { players }\end{array}$ & $\begin{array}{l}\text { IG: } 11 \text { teams; } \\
223 \text { players } \\
\text { CG: } 12 \text { teams; } \\
233 \text { players } \\
\text { Total: } 23 \text { teams; } \\
456 \text { players }\end{array}$ & $\begin{array}{l}\text { IG: } \\
21605 \text { hours* } \\
\text { CG: } \\
22647 \text { hours* }\end{array}$ & $\begin{array}{l}\text { IG: } 207 \\
\text { injuries } \\
\text { CG: } 220 \\
\text { injuries }\end{array}$ \\
\hline \multirow[t]{4}{*}{ FIFA $11+$} & $\begin{array}{l}\text { Soligard et al } \\
(2008)^{11}\end{array}$ & $\begin{array}{l}\text { Female, youth } \\
\text { (13-17 years) }\end{array}$ & $\begin{array}{l}\text { The } 11+: \text { a } 20 \text { min } \\
\text { exercise programme } \\
\text { for trunk and lower } \\
\text { extremity with } \\
\text { progression levels }\end{array}$ & $\approx 8$ & $\begin{array}{l}\text { IG: } 65 \text { teams; } \\
1320 \text { players } \\
\text { CG: } 60 \text { teams; } \\
1220 \text { players } \\
\text { Total: } 125 \text { teams; } \\
2540 \text { players }\end{array}$ & $\begin{array}{l}\text { IG: } 52 \text { teams; } \\
1055 \text { players } \\
\text { CG: } 41 \text { teams; } \\
837 \text { players } \\
\text { Total: } 93 \text { teams; } \\
1892 \text { players }\end{array}$ & $\begin{array}{l}\text { IG: } \\
49899 \text { hours } \\
\text { CG: } \\
45428 \text { hours }\end{array}$ & $\begin{array}{l}\text { IG: } 161 \\
\text { injuries† } \\
\text { CG: } 215 \\
\text { injuriest }\end{array}$ \\
\hline & $\begin{array}{l}\text { Owoeye et al } \\
(2014)^{40}\end{array}$ & $\begin{array}{l}\text { Male, youth } \\
\text { (14-19 years) }\end{array}$ & & $\approx 6$ & $\begin{array}{l}\text { IG: } 10 \text { teams; } 212 \\
\text { players } \\
\text { CG: } 10 \text { teams; } 204 \\
\text { players } \\
\text { Total: } 20 \text { teams; } \\
416 \text { players }\end{array}$ & $\begin{array}{l}\text { IG: } 10 \text { teams; } \\
212 \text { players } \\
\text { CG: } 10 \text { teams; } \\
204 \text { players } \\
\text { Total: } 20 \text { teams; } \\
416 \text { players }\end{array}$ & $\begin{array}{l}\text { IG: } \\
51017 \text { hours } \\
\text { CG: } \\
61045 \text { hours }\end{array}$ & $\begin{array}{l}\text { IG: } 36 \\
\text { injuries } \\
\text { CG: } 94 \\
\text { injuries }\end{array}$ \\
\hline & Hammes $(2014)^{33}$ & $\begin{array}{l}\text { Male, veteran } \\
\text { ( } \geq 32 \text { years) }\end{array}$ & & $\approx 9$ & $\begin{array}{l}\text { IG: } 10 \text { teams; } 158 \\
\text { players } \\
\text { CG: } 10 \text { teams; } 125 \\
\text { players } \\
\text { Total: } 20 \text { teams; } \\
383 \text { players }\end{array}$ & $\begin{array}{l}\text { IG: } 9 \text { teams; } \\
146 \text { players } \\
\text { CG: } 9 \text { teams; } \\
119 \text { players } \\
\text { Total: } 18 \text { teams; } \\
265 \text { players }\end{array}$ & $\begin{array}{l}\text { IG: } 4172 \text { hours } \\
\text { CG: } 2937 \text { hours }\end{array}$ & $\begin{array}{l}\text { IG: } 51 \\
\text { injuries } \\
\text { CG: } 37 \\
\text { injuries }\end{array}$ \\
\hline & $\begin{array}{l}\text { Silvers-Granelli } \\
\text { et al }(2015)^{43}\end{array}$ & $\begin{array}{l}\text { Male } \\
\text { (18-25 years) }\end{array}$ & & $\approx 5$ & $\begin{array}{l}\text { IG: } 31 \text { teams; } 775 \\
\text { players } \\
\text { CG: } 34 \text { teams; } 850 \\
\text { players } \\
\text { Total: } 65 \text { teams; } \\
1625 \text { players }\end{array}$ & $\begin{array}{l}\text { IG: } 27 \text { teams; } \\
675 \text { players } \\
\text { CG: } 34 \text { teams; } \\
850 \text { players } \\
\text { Total: } 61 \text { teams; } \\
1525 \text { players }\end{array}$ & $\begin{array}{l}\text { IG: } \\
52839 \text { hours } \\
\text { CG: } \\
66318 \text { hours } ¥\end{array}$ & $\begin{array}{l}\text { IG: } 285 \\
\text { injuries } \\
\text { CG: } 665 \\
\text { injuries }\end{array}$ \\
\hline
\end{tabular}

${ }^{*}$ Data on exposure provided by authors.

tData on overall injuries provided by authors.

‡Data on exposure provided by authors and calculated from athletic exposure ( $1 \mathrm{AE}=1.5$ hours).

CG, Control group; IG, Intervention group; RCT, randomised controlled trial.

inflation factor (IF). The equation for cluster adjustment is IF $=1$ $+(n-1) \rho$, where $\rho$ is the ICC, $n$ the average cluster size and IF the inflation factor. ${ }^{16}{ }^{17}$ Effective sample size was then calculated by dividing the number of injuries and exposure hours by IF, as described in the Cochrane Handbook for Systematic Review of Interventions, V.5.1 (part 3: 16.3.4). ${ }^{17}$

For the primary and secondary analyses including all randomised studies using FIFA injury prevention programmes, the overall injury IRR and 95\% CIs were estimated as the relative effect size. In the secondary analyses on body region-specific injury rates, we only included studies using the FIFA $11+$ prevention programme, and IRR and 95\% CIs were estimated as the relative effect size using the extracted and pooled injury data from the following body regions: lower limb, hamstring, hip/groin, knee, and ankle, analysed in five separate analyses, one for each body region.

Stata V.12 (StataCorp LP) was used to perform the meta-analysis and calculate the pooled estimates. A forest plot is presented to allow for visual comparisons between studies. The level of statistical heterogeneity for pooled data was established using the $\chi^{2}$ and $\mathrm{I}^{2}$ statistics. The $\chi^{2}$ and $\mathrm{I}^{2}$ statistics describe heterogeneity or homogeneity of the comparisons with $\mathrm{p}<0.05$ indicating a significant heterogeneity. ${ }^{18}$ The
Mantel-Haenszel ${ }^{19}{ }^{20}$ random-effects method was selected for all analyses.

Compliance with the FIFA injury prevention programmes and its relation to football injury rates

To assess the association between prevention programme compliance and effect on injury incidence, we performed two random-effects meta-regression analyses using Stata. One meta-regression was performed using the injury incidence in the intervention group as the outcome and the average team compliance in each study as the explanatory variable. The post hoc meta-regression was performed to investigate the association between IRR from each study as the outcome and the average team compliance from each study as the explanatory variable.

Harms resulting from the execution of the FIFA injury prevention programmes

Adverse effect/harms of applying an FIFA injury prevention programme was given as number and type(s) of adverse effects resulting from the actual execution of the FIFA injury prevention programmes (experienced while performing the prevention exercises) relative to the total number of players performing the FIFA injury prevention programmes in the included studies. 


\section{Risk of bias assessment}

The included cluster-randomised studies were assessed for risk of bias by two independent raters (EE and $\mathrm{MBC}$ ) using the Cochrane Collaboration's tool for assessing risk of bias in randomised controlled trials. ${ }^{17}$ Each trial was evaluated across seven domains of bias, including one or more items that were appraised in two parts. First, the relevant trials' characteristics related to the item were summarised. Second, each bias domain was judged as high or low risk of bias according to its possible effect on the results of the trial. When the possible effect was unknown or insufficient detail was reported, the item was judged as unclear. All the above concerning risk of bias followed the description outlined in the Cochrane Handbook for Systematic Review of Interventions, V.5.1 (part 2: 8.5.1). ${ }^{17}$ Since only cluster-randomised trials were included, particular types of bias were assessed in the 'other bias' domain for all studies, according to how to assess risk of bias in clusterrandomised trials following the recommendations in the Cochrane Handbook for Systematic Review of Interventions, V.5.1 (part 3: 16.3.2). ${ }^{17}$ Any disagreements between ratings were resolved by discussion between the raters. Consultation with a third party (EMB) was to be used if disagreements still persisted after this discussion. An assessment of the methodological quality was not performed, because no evidence for such appraisals and judgements exists as to why such an assessment could be potentially misleading. ${ }^{17}$

High risk of bias is to be expected from the domains concerning blinding of participants and researchers (performance bias), and blinding of outcome assessment (detection bias). In prevention studies using active exercise programmes such as the FIFA injury prevention programmes, it is very difficult to blind the participants to the intervention. Furthermore, it is impossible to blind the outcome assessment as the reporting of injuries is self-reported by definition. Risk of bias assessment was therefore followed as recommended in the Cochrane Handbook for Systematic Review of Interventions, V.5.1 (part 2: 8.5.1 and part 3: 16.3.2), ${ }^{17}$ but not considered for sensitivity analyses in the final evaluation of the primary or the secondary outcomes. Intertester reliability of ratings was calculated and presented using percentage of agreement and unweighted $\kappa$ statistics.

\section{RESULTS}

The literature search yielded 2400 studies after removal of duplicates. Out of these, 51 were considered for inclusion after review of title and abstract. Following a full-text review, 19 reports were excluded due to 11 not qualifying as full-text articles, and 8 because they did not include football players performing the FIFA injury prevention programmes. This left 32 studies investigating the FIFA injury prevention programmes, including potential harms. ${ }^{9} 11 \quad 12 \quad 21-49$ Out of these, 26 studies were not cluster-randomised trials or randomised controlled trials on FIFA injury prevention programmes, leaving 6 studies $^{11} 1221334043$ for the assessment of the effect of the FIFA injury prevention programmes on football injury rates in players playing at the recreational/subelite level (figure 2). None of these six studies included players at the elite level. Two studies involved the FIFA 11 prevention programme, ${ }^{12} 21$ and four studies involved the FIFA $11+$ prevention programme. $^{11334043}$

\section{Effect of FIFA injury prevention programmes on football injury rates}

The six included randomised controlled trials had randomly allocated 186 teams (3806 football players) to FIFA injury
Figure 2 Flow chart of study selection for the analysis of the effects of the FIFA injury prevention programmes on injury prevention, and possible adverse events related to these programmes. RCT, randomised controlled trial.
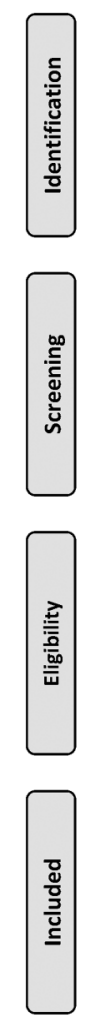

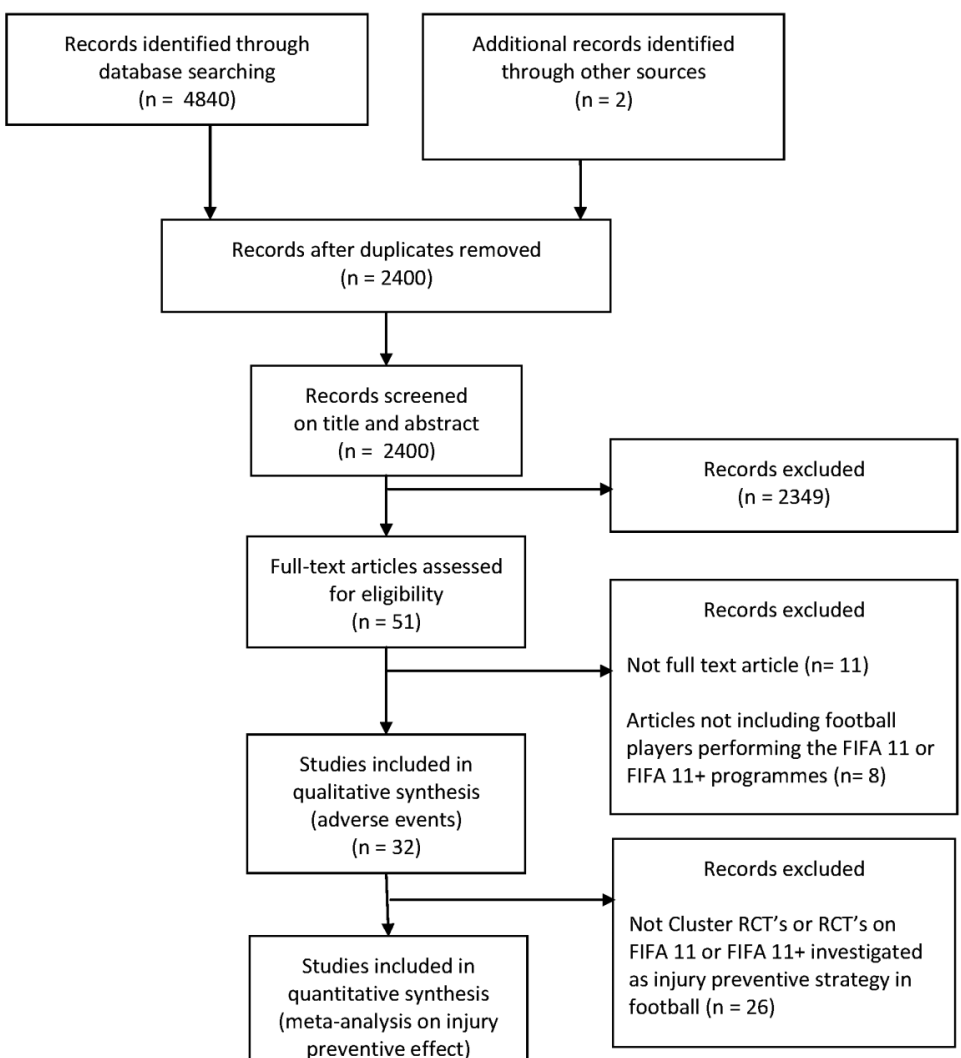

$(n=6)$ 
prevention programmes, and 180 teams (3645 players) to the control group (no programme).

\section{Study characteristics}

The mean age of players in the individual trials ranged from 15 to 45 years. The follow-up time for the trials included periods of 5-9 months (table 1).

\section{Synthesis of results}

By pooling data of 6574 individuals playing football at the recreational/subelite level, 510.055 exposure hours and 2454 overall injuries were collected from the six included randomised controlled trials. The pooled total injury incidence was 3.99 injuries per 1000 hours of exposure for the intervention group and 5.57 injuries per 1000 hours of exposure for the control group.

In the primary analysis, and for the primary outcome (overall injury rate), the pooled results showed a $25 \%$ overall injury reduction per 1000 hours of exposure in the FIFA injury prevention programmes (FIFA 11 and FIFA 11+) group compared with the control group (IRR $0.75 ; 95 \%$ CI 0.57 to 0.98 , $\mathrm{p}=0.036$; figure 3$)$. There was significant heterogeneity in this analysis $\left(\mathrm{I}^{2}=68.9 \%, \mathrm{p}=0.007\right)$.

In the secondary analyses (type of programme), for the primary outcome (overall injury rate) the pooled results showed injury reduction per 1000 hours of exposure in the FIFA 11+ programme group compared with the control group (IRR 0.61; $95 \%$ CI 0.48 to $0.77, \mathrm{p}<0.001, \mathrm{I}^{2}=25.5 \%, \mathrm{p}=0.259$ ), but no significant reduction in the FIFA 11 programme group (IRR $0.99 ; 95 \%$ CI 0.80 to $1.23, p=0.940, \mathrm{I}^{2}=0.0 \%, \mathrm{p}=0.982$ ) compared with the control group (figure 4).

In the secondary analyses (body region) for the secondary outcome (region-specific injury rates) associated with the FIFA $11+$ programme, an overall injury reduction existed in favour of the FIFA $11+$ programme for lower limb injuries (IRR 0.63; $95 \%$ CI 0.48 to $\left.0.81, \mathrm{p}<0.001, \mathrm{I}^{2}=28.1 \%, \mathrm{p}=0.243\right)$. More specifically, an overall injury reduction existed in favour of the FIFA $11+$ programme for the following body region-specific outcomes: hamstring injuries (IRR $0.40 ; 95 \%$ CI 0.19 to 0.84 , $\mathrm{p}=0.016, \mathrm{I}^{2}=0.0 \%, \mathrm{p}=0.627$ ), hip/groin injuries (IRR 0.59; $95 \%$ CI 0.35 to $\left.0.97, \mathrm{p}=0.037, \mathrm{I}^{2}=0.0 \% \%, \mathrm{p}=0.350\right)$, knee injuries (IRR 0.52 ; $95 \%$ CI 0.38 to $0.72, \mathrm{p}<0.001, \mathrm{I}^{2}=0.0 \%$, $\mathrm{p}=0.573$ ) and ankle injuries (IRR $0.68 ; 95 \%$ CI 0.48 to 0.97 , $\mathrm{p}=0.035, \mathrm{I}^{2}=27.1 \%, \mathrm{p}=0.254$; figure 5).

\section{Compliance}

Four of the six studies included information in the methods section concerning the FIFA 11 injury prevention programmes (FIFA $11+$ and FIFA 11) which specified that the programme should be performed at least twice a week. ${ }^{11} 124043$ This is in accordance with the recommendation from F-MARC on the execution of FIFA injury prevention programmes (http://www. f-marc.com/11plus/11plus/).

\section{Study characteristics}

For the six cluster-randomised studies, the average number of FIFA injury prevention programme sessions per week performed by included intervention teams was $1.2(\mathrm{SD} \pm 0.7)$ sessions/week. From information on 158 intervention teams from five studies, ${ }^{11} 12213343$ out of 168 intervention teams from all six included studies in total, ${ }^{11} 1221334043$ the number of FIFA injury prevention programmes sessions conducted on average per week at team level was obtained: $15 \%$ of teams did less than half a session per week, $53 \%$ did less than one session per week, $72 \%$ did less than one and a half sessions per week, and $87 \%$ did less than two sessions per week, meaning that $13 \%$ of all intervention clubs reached the suggested minimum of at least two sessions per week.

\section{Synthesis of results}

There was no significant association between average compliance in the individual studies and the overall injury incidence estimate from the intervention group in each study (adjusted $\left.\mathrm{R}^{2}=-18.8 \%, \mathrm{p}=0.670\right)$. The post hoc meta-regression showed no significant association between compliance and IRR from each study (adjusted $\mathrm{R}^{2}=72.4 \%, \mathrm{p}=0.107$ ). However, the direction of this non-significant association did point towards a higher preventative effect among the studies with higher compliance.

\section{Risk of bias}

Agreement by raters on risk of bias decisions for the six included cluster-randomised controlled studies was $78 \%$ (unweighted $\kappa$ 0.66) for the six main risk of bias domains. All

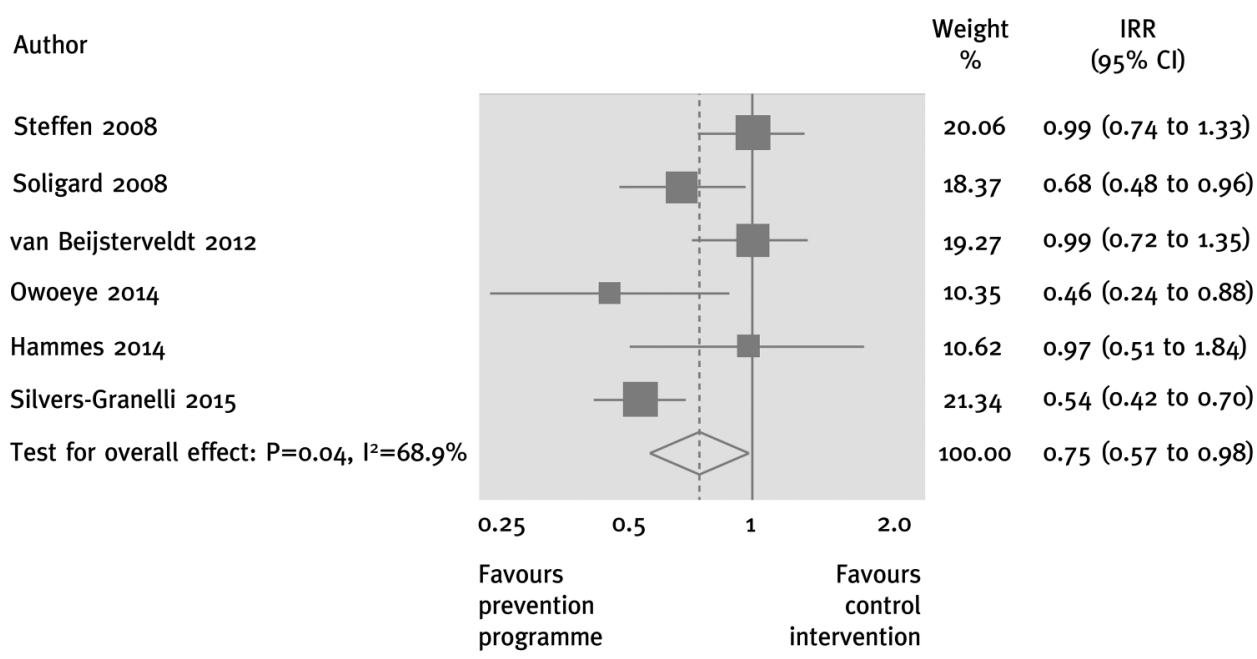

Figure 3 Primary analysis of overall injury rates in FIFA injury prevention programmes compared with control intervention. IRR, incidence rate ratio. 
Figure 4 Secondary analysis of overall injury rates for FIFA 11 and FIFA $11+$, respectively, compared with control intervention. IRR, incidence rate ratio.

\section{FIFA 11}

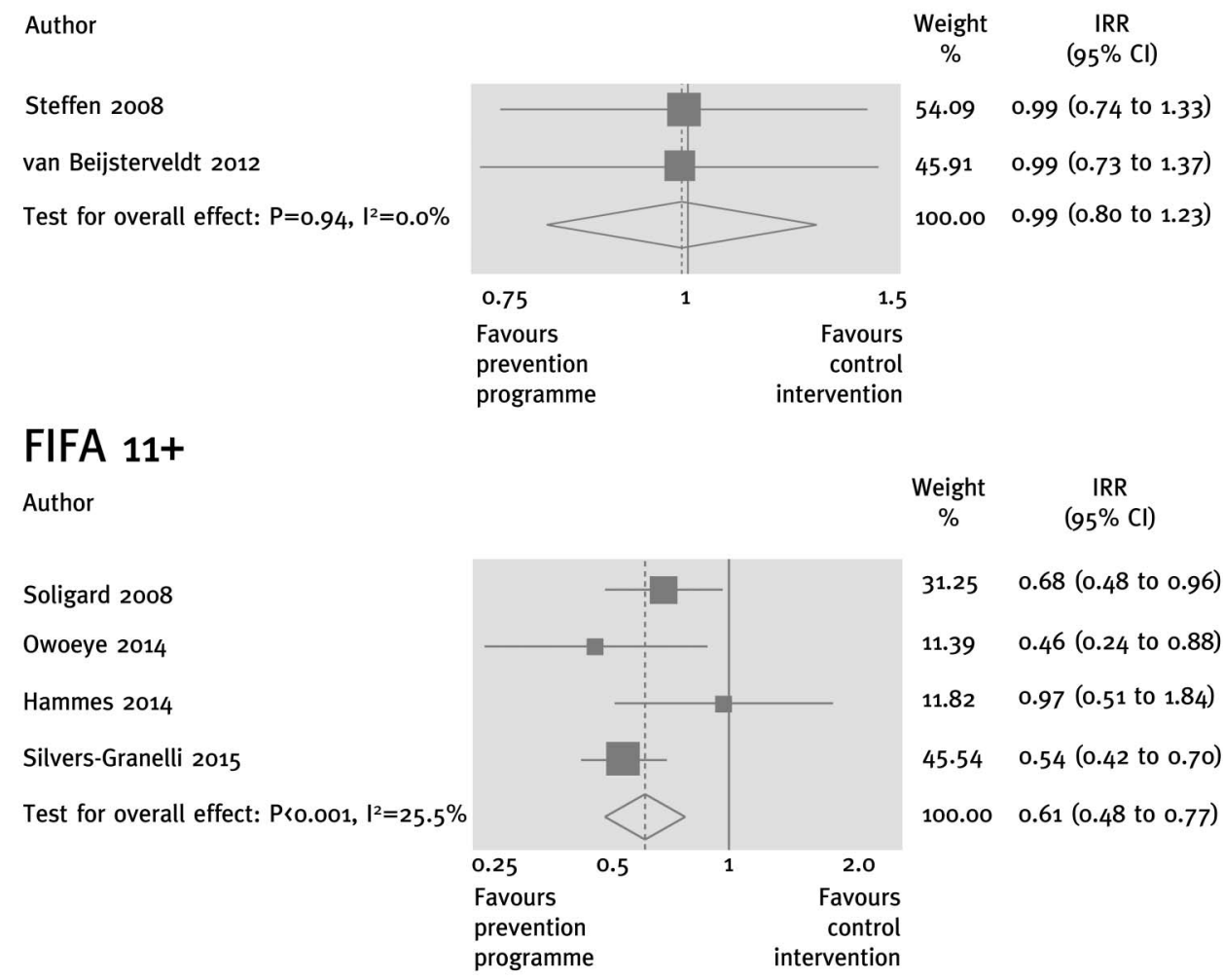

disagreements were caused by reading errors, where one of the reviewers had overlooked specific information. The two reviewers resolved all disagreements and no third reviewer involvement was needed for achieving consensus. Judgements on the domain 'other bias' were discussed among the reviewers for all six studies. All studies were assessed as having a high risk of bias in at least three domains (see online supplementary table S2). In all studies, neither intervention providers nor intervention receivers (performance bias), or outcome assessment in the form of self-reported injury (detection bias), could be considered blinded (see online supplementary table S2).

\section{Harms}

None of the 32 studies included preplanned and standardised registration of information on adverse events.

\section{Study characteristics}

Out of all 32 studies $^{9} 111221-49$ including information on practical execution of the FIFA injury prevention programmes, only one cluster-randomised trial ${ }^{11}$ commented on possible harms (adverse events).

\section{Synthesis of results}

In relation to the total number of players performing the FIFA injury prevention programmes $(n=4594)$, only one report of a minor hamstring strain was mentioned in the discussion section. ${ }^{11}$

\section{DISCUSSION}

In this systematic review and meta-analysis where the primary outcome was the overall injury incidence, we found a statistically significant reduction in football injuries in recreational/subelite football players in favour of the FIFA injury prevention programmes compared with controls (no programme). The secondary analyses revealed that significant effects were found when pooling data from studies applying the FIFA $11+$ prevention programme, whereas no significant effects were found when pooling data from studies applying the FIFA 11 prevention programme.

\section{Level 1 evidence on the effect of FIFA injury prevention programmes}

One previous systematic review including a meta-analysis by $\mathrm{Al}$ Attar et $a l^{14}$ was published in 2015. The study investigated the benefits of FIFA injury prevention programmes in footballers. While this study reported very similar overall injury reduction estimates to those of this study, the analyses and conclusions in the study by Al Attar $e t$ al ${ }^{14}$ were based on studies different from those included in the current review and meta-analysis. They included both randomised and observational studies in their meta-analysis, ${ }^{14}$ and thus did not separate meta-analyses on cluster-randomised/randomised controlled studies from analyses made on observational studies, as recommended in the Cochrane Handbook for Systematic Review of Interventions. ${ }^{17}$ Furthermore, cluster-adjusted estimates were not calculated by Al Attar $e t a l,{ }^{14}$ which means that the effective sample size was never taken into account. ${ }^{16}$ These are central points when performing systematic reviews including meta-analyses, which we have previously addressed in a letter to the editor, ${ }^{50}$ since we were concerned about the confidence one could have in the robustness of the estimates considering the statistical approach applied by Al Attar et al. ${ }^{14}$ To the best of our knowledge, this study is therefore the first systematic review and meta-analysis to exclusively provide level 1 evidence from cluster-randomised studies in a pooled meta-analysis and, furthermore, to account for possible cluster effects to the same extent shown by Soligard et $a l^{11}$ to be present among the teams in their large prevention study. 

injury rates in relation to conducting the FIFA $11+$ prevention programme the following specific body regions: hamstring, hip/groin, knee, and ankle. IRR, incidence rate ratio.
Figure 5 Secondary analyses of compared with control intervention for

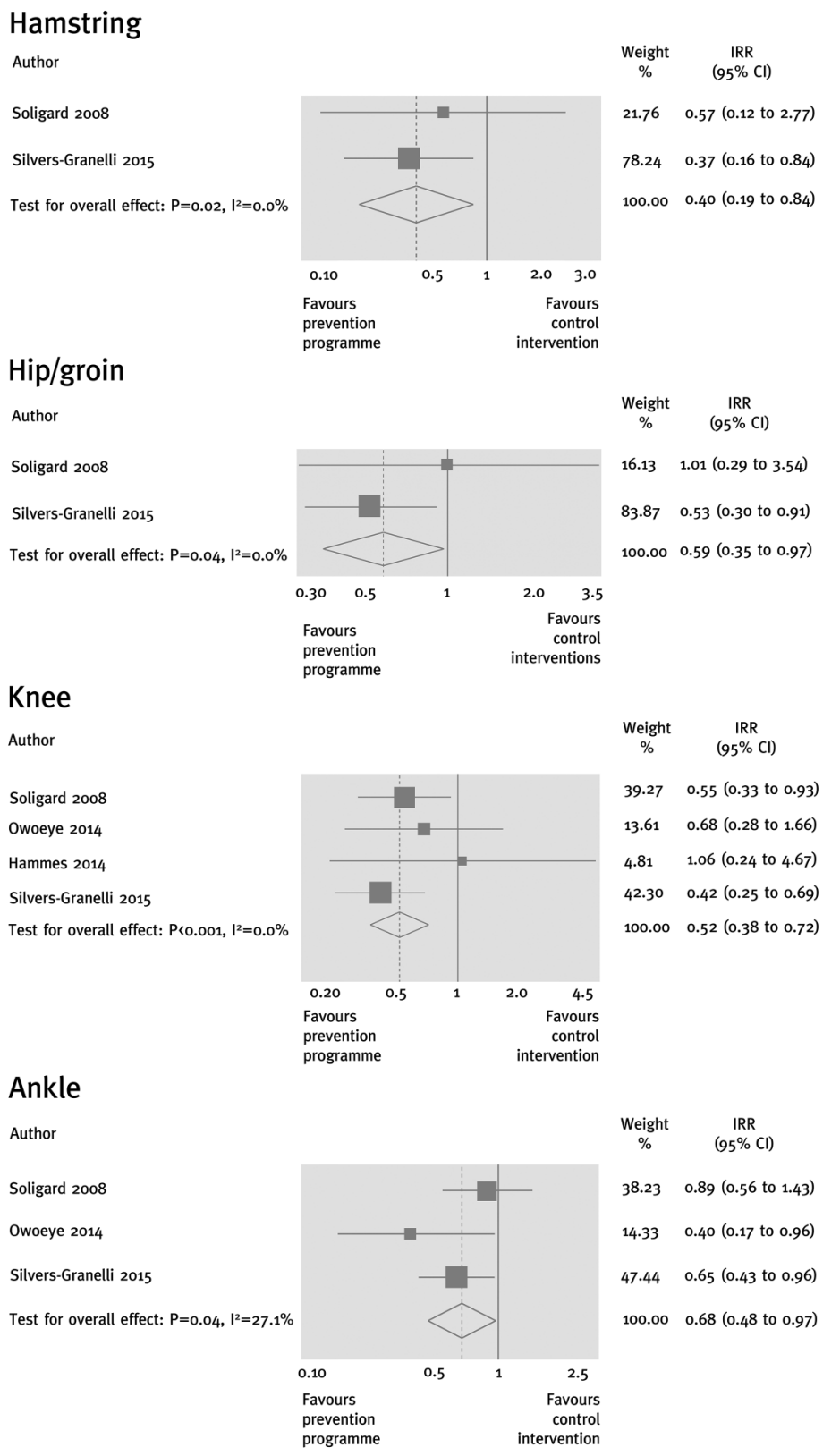

The FIFA 11 prevention programme versus the FIFA 11+ prevention programme

Our study documents that cluster-randomised studies of FIFA injury prevention programmes, when pooled together, show a substantial injury reduction in recreational/subelite football. This effect seems to be primarily driven by the large effect of the FIFA $11+$ prevention programme, as the initially introduced FIFA 11 prevention programme alone does not seem to induce any injury-reducing effect. The heterogeneity analyses also support this notion, as significant heterogeneity between FIFA injury prevention programme studies only exists when pooling studies including FIFA 11 and FIFA 11+ together, and disappears when pooling FIFA 11 and FIFA $11+$ prevention programme studies separately. This suggests that effect sizes from the studies including these two different programmes are diverse. This diversity cannot be investigated or explained by differences in the methodology used in these studies, as all studies have similar issues concerning risk of bias.
What modulates the injury-preventing effect of the FIFA $11+$ programme: compliance or conditioning?

The finding of no injury-preventing effect from the FIFA 11 prevention programme in the large study by Steffen $e$ t $a l^{12}$ was initially suggested to be due to the low compliance. This was, however, somehow contradicted by the findings of van Beijsterveldt et al, ${ }^{21}$ which also did not show any injurypreventing effect of the FIFA 11 prevention programme, despite having a much higher team compliance than the study of Steffen et al. ${ }^{12}$ The findings of this study did not reveal any statof sessions performed per week at team level) and overall injury incidence, or overall injury IRR, although the post hoc analysis (using IRR) did point towards the possibility of a higher preventative effect among the studies with the highest team compliance. Two studies on the FIFA 11+ programme have indicated, within the same study context (female adolescent footballers) and injury definition, that there is an association between istically significant association between compliance (the number 
individual player compliance (number of sessions performed) and an overall injury- preventing effect. ${ }^{44}{ }^{47}$ The indications from these studies suggest that FIFA $11+$ is the most efficacious in individuals with higher compliance rates. ${ }^{44} 47$ Importantly, all studies ${ }^{11} 1221334043$ included in the present systematic review and meta-analysis showed poor overall team compliance in terms of achieving the minimally suggested prevention programme dosage of at least two weekly team sessions. Only $13 \%$ of all teams from the included studies reached this benchmark. Getting at least two team sessions a week may therefore still be important to achieve the optimal effect, which is further supported by the fact that physiological and performance improvements documented from the FIFA $11+$ programme were obtained from studies where football players were performing the prevention programmes 2-3 times a week for 8-12 weeks. $^{23}{ }^{25-30} 34$ Several FIFA 11+ programme studies have shown improvements in quadriceps and hamstring muscle strength, as well as in balance, agility and running speed, after only $8-12$ weeks execution of the FIFA $11+$ prevention programme compared with a control group with no warm-up programme. ${ }^{23}{ }^{25-30} 34$ In contrast, the much less strenuous FIFA 11 prevention programme seems to induce no or only minimal physiological adaptations in quadriceps and hamstring strength, as well as in balance, agility or running speed. ${ }^{12} 45$ In this context, we speculate that the large difference in prescribed exercise intensity between the FIFA 11 and the FIFA $11+$ prevention programmes could also provide a possible explanation for the discrepancy in injury-preventing effects between the two programmes. Accordingly, despite similar exercises being included in both programmes, the FIFA $11+$ includes much higher loads/skill levels, longer active muscle contractions (time under muscle tension) and/or more repetitions for these type of exercises (figure 1). By introducing three exercise progression levels in the FIFA $11+$ for each exercise, the number of repetitions and the time under tension for the strength training exercises alone are increased 2-3 times when a player exercises at levels 2 and $3 .^{11} 12$

\section{Harms related to the execution of FIFA injury prevention programmes}

We also searched the literature for information on harms (adverse events) associated with the execution of the FIFA injury prevention programmes, and we included all studies published from 2004 onwards. We only found one report of injury on 4594 players performing the FIFA injury programmes. Based on the lack of preplanned and standardised registration of adverse events related to the FIFA injury prevention programmes, it is questionable how meaningful this result is. Future FIFA injury prevention programme studies need to ensure a more stringent and transparent reporting of adverse events related to the prevention programme, as it cannot be assumed that this is negligible based on reports from existing studies.

\section{The FIFA 11+ prevention programme works in controlled studies-now it is time for adoption and implementation!}

An injury-preventing effect of $25 \%$ was present when conducting the FIFA injury prevention programmes compared with following the usual training and match routines in recreational/ subelite football, but no clinically meaningful conclusion can be drawn from this result due to the apparent diversity in effect sizes between studies looking at FIFA 11 and FIFA 11+ prevention programmes. More specifically, the FIFA $11+$ prevention programme was shown to have a substantial injury-preventing effect by reducing football injuries by $39 \%$, whereas a preventive effect from the FIFA 11 prevention programme alone could not be documented. Reducing injuries to this extent by using an exercise-based prevention programme has, furthermore, been shown to reduce injury-related costs in football by more than $40 \% .^{3651}$

At this point in time, very little information on the actual adoption and implementation of the FIFA injury prevention programmes exists. Data from a few preliminary studies suggest that it may not be realistic to transfer the results from this study to elite football where application, relevance, dosage and intensity need to be specifically defined and adapted to the elite environment. ${ }^{52-56}$ More research and information on how to optimise adoption and implementation of FIFA $11+$ at all levels should therefore be given high priority in the future, as positive effects from this prevention programme are now well documented. Providing substantial level 1 evidence-based information for the programme's preventive effects and for the injury-related cost that can be saved from using the programme is among the first important steps towards worldwide adoption and implementation. Furthermore, the information needs to reach health and football policymakers in order to highlight and encourage the importance of adopting and implementing the FIFA 11+ prevention programme at all recreational levels of football, as football is globally the most popular sport, and is an excellent form of physical activity. Football is, as such, already documented to be one of the most potent physical activities to induce important health benefits such as cardiovascular and metabolic health across ages and genders; ${ }^{3}$ thus, reducing football injuries associated with this form of activity is crucial.

\section{Methodological limitations and considerations}

A limitation of this study is that the included studies in the meta-analyses use different injury definitions. While four out of the six included studies only report 'time-loss' injuries, the remaining two studies report all injuries. Although such a discrepancy in injury definitions can provide different injury incidences between studies, it should not affect the IRR within randomised controlled trials. Furthermore, we did not assess statistically for publication bias (tests for funnel plot asymmetry) due to the low number of included studies in our meta-analyses. This is, however, in accordance with the Cochrane Handbook for Systematic Review of Interventions, V.5.1 (part 2: 10.4.3), where tests for funnel plot asymmetry are only recommended when there are at least 10 studies included in the meta-analysis. ${ }^{17}$

Despite not reaching the recommended dose, this study clearly shows that application of the FIFA $11+$ reduces injuries dramatically in recreational and subelite football, which relates to the majority of players worldwide. However, more studies on exercise intensity, dose-response relationship, as well as adoption, implementation and compliance with the FIFA $11+$ programme are called for to improve understanding of what the most important parameters are when we aim to adopt and implement the FIFA $11+$ programme at the different levels of football.

In conclusion, an injury-preventing effect of the FIFA injury prevention programmes compared with usual care (no injury prevention programme) was shown in football. This effect was induced by the FIFA $11+$ prevention programme which has a substantial injury-preventing effect by reducing football injuries to a clinically relevant $39 \%$. In contrast to this, a preventive effect of the FIFA 11 prevention programme could not be documented. 


\section{What are the findings?}

- The FIFA 11+ prevention programme has a substantial injury-preventing effect by reducing football injuries in recreational/subelite football by $39 \%$, whereas a preventive effect from the FIFA 11 prevention programme alone could not be documented.

- The FIFA 11+ prevention programme reduces the top four most prevalent football injuries: hamstring, hip/groin, knee and ankle injury by $60 \%, 41 \%, 48 \%$ and $32 \%$, respectively.

- Less than $15 \%$ of intervention teams from randomised controlled trials investigating the effect of FIFA injury prevention programmes reached the recommended dose of two sessions per week during the season. This suggests that there is room for improvement when it comes to optimal adoption and implementation of FIFA injury prevention programmes.

- Preplanned and standardised registration of adverse events related to the execution of FIFA injury prevention programmes are generally lacking. Possible adverse effects of the programmes have therefore not been sufficiently investigated at present.

\section{How might it impact on clinical practice in the future?}

- Since football induces important health benefits across gender and lifespan by improving cardiovascular and metabolic health, and preventing risk factors for lifestyle diseases, the prevention of injuries through implementing the FIFA 11+ prevention programme in recreational/subelite football is important to optimise the number of players who will achieve important health benefits from playing football.

- Through the provision of level 1 evidence-based information from the current study, worldwide adoption and implementation of the FIFA 11+ prevention programme should be further encouraged among all relevant partiesfrom health and football policymakers, stakeholders and associations to clubs, coaches and players at all recreational/ subelite levels of football.

- To support future adaptation and implementation of the FIFA 11+ programme, there is a need to focus on doseresponse relationships, compliance and potential adverse events in relation to the usage of the FIFA 11+ at different levels of football.

\footnotetext{
Author affiliations

'Department of Orthopaedic Surgery, Sports Orthopedic Research CenterCopenhagen (SORC-C), Amager-Hvidovre Hospital, Copenhagen University, Hvidovre, Denmark

${ }^{2}$ Department of Physical Medicine and Rehabilitation-Copenhagen (PMR-C), Amager-Hvidovre Hospital, Copenhagen University, Hvidovre, Denmark ${ }^{3}$ Research Unit for General Practice in Aalborg, Department of Clinical Medicine, Aalborg University, Aalborg, Denmark

${ }^{4}$ University School of Health and Sport Sciences, Universitat de Girona (EUSES-UdG), Carrer de Francesc Macia 65, Girona, Spain

${ }^{5}$ Sportclinic, Physiotherapy and Sports Training Center, Girona, Spain

${ }^{6}$ Department of Physiotherapy and Occupational Therapy, Faculty of Health and Technology, Metropolitan University College, Copenhagen N, Denmark

${ }^{7}$ The Parker Institute, Copenhagen University Hospital, Bispebjerg and Frederiksberg, Copenhagen, Denmark
}

${ }^{8}$ Department of Health Science and Technology, Center for Sensory-Motor Interaction, Aalborg University, Aalborg, Denmark

${ }^{9}$ Department of Occupational Therapy and Physiotherapy, Aalborg University Hospital, Aalborg, Denmark

\section{Twitter Follow Kristian Thorborg @KThorborg}

Contributors $\mathrm{KT}, \mathrm{KKK}, \mathrm{MBC}, \mathrm{EE}, \mathrm{EMB}$ and MSR all participated in the conception and design of the study. KT, KKK and EE were responsible for acquisition of data. MSR did the statistical analysis, and $\mathrm{KT}, \mathrm{KKK}, \mathrm{MBC}$, EE and EMB took part in the interpretation of the analysis. KT drafted the manuscript. All authors critically revised the manuscript for important intellectual content and approved the final version of the manuscript. KT is the guarantor.

Funding EMB is supported by the OAK foundation (grant number Ocay-07-264).

Competing interests None declared.

Provenance and peer review Not commissioned; externally peer reviewed.

Data sharing statement The statistical code and data set are available from the corresponding author.

\section{REFERENCES}

1 FIFA. FIFA big count 2006: 270 million people active in football. http://www.fifa. $\mathrm{com} / \mathrm{media} /$ news $/ \mathrm{y}=2007 / \mathrm{m}=5 /$ news =fifa-big-count-2006-270-million-people-activefootball-529882.html

2 Oja P, Titze S, Kokko S, et al. Health benefits of different sport disciplines for adults: systematic review of observational and intervention studies with meta-analysis. Br J Sports Med 2015:49:434-40.

3 Krustrup $P$, Bangsbo J. Recreational football is effective in the treatment of non-communicable diseases. Br J Sports Med 2015;49:1426-7.

4 Peterson L, Junge A, Chomiak J, et al. Incidence of football injuries and complaints in different age groups and skill-level groups. Am J Sports Med 2000;28:S51-7.

5 Powell JW, Barber-Foss KD. Injury patterns in selected high school sports: a review of the 1995-1997 seasons. J Athl Train 1999;34:277-84.

6 Bizzini M, Dvorak J. FIFA 11+: an effective programme to prevent football injuries in various player groups worldwide-a narrative review. Br J Sports Med 2015;49:577-9.

7 Baarveld F, Visser CA, Kollen BJ, et al. Sports-related injuries in primary health care. Fam Pract 2011:28:29-33.

8 Kisser R, Bauer R. The burden of sports injuries in the European Union. Research report D2h of the project "Safety in Sports". Vienna: Austrian Road Safety Board (Kuratorium für Verkehrssicherheit), 2012.

9 Junge $\mathrm{A}$, Lamprecht $\mathrm{M}$, Stamm $\mathrm{H}$, et al. Countrywide campaign to prevent soccer injuries in Swiss amateur players. Am J Sports Med 2011;39:57-63.

10 Barengo NC, Meneses-Echavez JF, Ramirez-Velez R, et al. The impact of the FIFA $11+$ training program on injury prevention in football players: a systematic review. Int J Environ Res Public Health 2014;11:11986-2000.

11 Soligard T, Myklebust G, Steffen K, et al. Comprehensive warm-up programme to prevent injuries in young female footballers: cluster randomised controlled trial. BMJ 2008;337:a2469.

12 Steffen $\mathrm{K}$, Myklebust G, Olsen OE, et al. Preventing injuries in female youth football -a cluster-randomized controlled trial. Scand J Med Sci Sports 2008:18:605-14.

13 Dvorak J, Junge A, Grimm K. Football medicine manual. Zurich: F-MARC, 2005

14 Al Attar WS, Soomro N, Pappas E, et al. How effective are F-MARC injury prevention programs for soccer players? A systematic review and meta-analysis. Sports Med 2016;46:205-17.

15 Liberati A, Altman DG, Tetzlaff J, et al. The PRISMA statement for reporting systematic reviews and meta-analyses of studies that evaluate healthcare interventions: explanation and elaboration. BMJ 2009:339:b2700.

16 Emery CA. Considering cluster analysis in sport medicine and injury prevention research. Clin J Sport Med 2007;17:211-14.

17 Higgins JPT. Cochrane handbook for systematic reviews of interventions version 5.1.0 [updated March 2011]. The Cochrane Collaboration, 2011. http://www cochrane-handbook org 2015

18 Higgins JP, Thompson SG, Deeks JJ, et al. Measuring inconsistency in meta-analyses. BMJ 2003;327:557-60.

19 Greenland S, Robins JM. Estimation of a common effect parameter from sparse follow-up data. Biometrics 1985;41:55-68.

20 Mantel N, Haenszel W. Statistical aspects of the analysis of data from retrospective studies of disease. J Nat/ Cancer Inst 1959:22:719-48.

21 van Beijsterveldt AM, van de Port IG, Krist MR, et al. Effectiveness of an injury prevention programme for adult male amateur soccer players: a cluster-randomised controlled trial. Br J Sports Med 2012;46:1114-18.

22 Bizzini M, Impellizzeri FM, Dvorak J, et al. Physiological and performance responses to the "FIFA 11+" (part 1): is it an appropriate warm-up? J Sports Sci 2013;31:1481-90.

23 Brito J, Figueiredo P, Fernandes L, et al. Isokinetic strength effects of FIFA's "The $11+"$ injury prevention training programme. Iso Exerc Sci 2010;18:211-15. 
24 Cloak R, Nevill A, Smith J, et al. The acute effects of vibration stimulus following FIFA $11+$ on agility and reactive strength in collegiate soccer players. J Sport Health Sci 2014;3:293-8.

25 da Costa Silva J, Fernandes da Silva J, do Nascimento Salvador P, et al. The effect of "FIFA 11+" on vertical jump performance in soccer players. Rev Bras Cineantropom Desempenho Hum 2015;17:733-41.

26 Daneshjoo A, Mokhtar AH, Rahnama N, et al. The effects of comprehensive warm-up programs on proprioception, static and dynamic balance on male soccer players. PLOS ONE 2012;7:e51568.

27 Daneshjoo A, Mokhtar AH, Rahnama N, et al. The effects of injury preventive warm-up programs on knee strength ratio in young male professional soccer players. PLOS ONE 2012;7:e50979.

28 Daneshjoo A, Rahnama N, Mokhtar AH, et al. Effectiveness of injury prevention programs on developing quadriceps and hamstrings strength of young male professional soccer players. J Hum Kinet 2013;39:115-25.

29 Daneshjoo A, Mokhtar AH, Rahnama N, et al. Effects of the 11+ and Harmoknee warm-up programs on physical performance measures in professional soccer players. J Sports Sci Med 2013;12:489-96.

30 Daneshjoo A, Mokhtar A, Rahnama N, et al. The effects of injury prevention warm-up programmes on knee strength in male soccer players. Biol Sport 2013;30:281-8.

31 Gatterer H, Ruedl G, Faulhaber M, et al. Effects of the performance level and the FIFA "11" injury prevention program on the injury rate in Italian male amateur soccer players. J Sports Med Phys Fit 2012;52:80-4.

32 Grooms DR, Palmer T, Onate JA, et al. Soccer-specific warm-up and lower extremity injury rates in collegiate male soccer players. J Athl Train 2013;48:782-9.

33 Hammes D, Aus Der FK, Kaiser $S$, et al. Injury prevention in male veteran football players - a randomised controlled trial using "FIFA 11+". J Sports SCi 2015;33:873-81.

34 Impellizzeri FM, Bizzini M, Dvorak J, et al. Physiological and performance responses to the FIFA 11+ (part 2): a randomised controlled trial on the training effects. J Sports Sci 2013:31:1491-502.

35 Kilding AE, Tunstall $H$, Kuzmic D. Suitability of FIFA's "The 11" training programme for young football players-impact on physical performance. J Sports Sci Med 2008;7:320-6.

36 Krist MR, van Beijsterveldt AMC, Backx FJG, et al. Preventive exercises reduced injury-related costs among adult male amateur soccer players: a cluster-randomised trial. J Physiother 2013;59:15-23.

37 Marshall PW, Cross R, Lovell R. Passive heating following the prematch warm-up in soccer: examining the time-course of changes in muscle temperature and contractile function. Physiol Rep 2015;3:e12635.

38 McKay CD, Steffen K, Romiti M, et al. The effect of coach and player injury knowledge, attitudes and beliefs on adherence to the FIFA 11+ programme in female youth soccer. Br J Sports Med 2014;48:1281-6.

39 Nakase J, Inaki A, Mochizuki T, et al. Whole body muscle activity during the FIFA $11+$ program evaluated by positron emission tomography. PLOS ONE 2013;8: e73898.

40 Owoeye OB, Akinbo SR, Tella BA, et al. Efficacy of the FIFA 11+ warm-up programme in male youth football: a cluster randomised controlled trial. J Sports Sci Med 2014;13:321-8.
41 Reis I, Rebelo A, Krustrup P, et al. Performance enhancement effects of federation internationale de football association's "the 11+" injury prevention training program in youth futsal players. Clin J Sport Med 2013;23:318-20.

42 Saho $Y$, Setojima $M$, Ogai $T$, et al. Efficacy of the injury prevention program "The $11 "$ and "The Modified 11" in collegiate soccer teams. Japan J Clin Sports Med 2011;19:314-21.

43 Silvers-Granelli $H$, Mandelbaum B, Adeniji 0 , et al. Efficacy of the FIFA 11+ injury prevention program in the collegiate male soccer player. Am J Sports Med 2015;43:2628-37.

44 Soligard T, Nilstad A, Steffen K, et al. Compliance with a comprehensive warm-up programme to prevent injuries in youth football. Br J Sports Med 2010;44: 787-93.

45 Steffen K, Bakka HM, Myklebust G, et al. Performance aspects of an injury prevention program: a ten-week intervention in adolescent female football players. Scand J Med Sci Sports 2008;18:596-604.

46 Steffen $\mathrm{K}$, Meeuwisse WH, Romiti M, et al. Evaluation of how different implementation strategies of an injury prevention programme (FIFA 11+) impact team adherence and injury risk in Canadian female youth football players: a cluster-randomised trial. Br J Sports Med 2013;47:480-7.

47 Steffen K, Emery CA, Romiti M, et al. High adherence to a neuromuscular injury prevention programme (FIFA 11+) improves functional balance and reduces injury risk in Canadian youth female football players: a cluster randomised trial. Br J Sports Med 2013;47:794-802.

48 Takata $Y$, Nakase J, Inaki A, et al. Changes in muscle activity after performing the FIFA 11+ programme part 2 for 4 weeks. J Sports Sci 2016;34:2011-17.

49 Whittaker JL, Emery CA. Impact of the FIFA $11+$ on the structure of select muscles in adolescent female soccer players. Phys Ther Sport 2015;16:228-35.

50 Thorborg K, Krommes K, Esteve E, et al. High risk of bias and low transparency in 'how effective are F-MARC injury prevention programs for soccer players? A systematic review and meta-analysis. Sports Med 2016;46:293-4.

51 Marshall DA, Lopatina E, Lacny $S$, et al. Economic impact study: neuromuscular training reduces the burden of injuries and costs compared to standard warm-up in youth soccer. Br J Sports Med 2016;50:1388-93.

52 O'Brien J, Finch CF. Injury prevention exercise programmes in professional youth soccer: understanding the perceptions of programme deliverers. BMJ Open Sports Exerc Med 2016:2:e000075.

53 McCall A, Carling C, Nedelec M, et al. Risk factors, testing and preventative strategies for non-contact injuries in professional football: current perceptions and practices of 44 teams from various premier leagues. $\mathrm{Br}$ I Sports $\mathrm{Med}$ 2014;48:1352-7

54 McCall A, Davison M, Andersen TE, et al. Injury prevention strategies at the FIFA 2014 World Cup: perceptions and practices of the physicians from the 32 participating national teams. Br J Sports Med 2015;49:603-8.

55 McCall A, Carling C, Davison M, et al. Injury risk factors, screening tests and preventative strategies: a systematic review of the evidence that underpins the perceptions and practices of 44 football (soccer) teams from various premier leagues. Br J Sports Med 2015;49:583-9.

56 McCall A, Dupont G, Ekstrand J. Injury prevention strategies, coach compliance and player adherence of 33 of the UEFA Elite Club Injury Study teams: a survey of teams' head medical officers. Br J Sports Med 2016:50:725-30. 